administered DW 75 is not absorbed with sufficient rapidity nor in sufficient quantity to be of any value in assessing adrenocortical integrity.

The significance of the relatively high levels of plasma 11OHCS at four and six hours after intravenous administration of DW 75 in the steroid-treated subjects again probably reflects the longer duration of this compound compared with that of Synacthen.

Our results have confirmed those of Jenny et al. (1966) that DW 75 has powerful adrenocortical stimulating properties. However, these workers also found that intramuscular injection of the compound resulted in a sustained rise in plasma 11-OHCS similar to that following intravenous administration. It is obvious that more subjects will have to be studied in order to resolve this discrepancy.

DW 75 has no obvious advantages over Synacthen in assessing adrenocortical function on the basis of a 30-minute test, nor can its duration of action compare with that of Synacthen Depot (Besser et al., 1967 ; Nelson et al., 1968), but its intermediate duration of activity may be useful in assessing depressed adrenals without priming the glands as could well happen with the long-acting preparations of corticotrophin.

We wish to thank Dr. W. Watson Buchanan and Dr. J. A. Boyle for advice and helpful criticism. The work was supported in part by a grant from the Arthritis and Rheumatism Council. We are grateful to Dr. D. S. Freestone, of Sandoz Ltd., for supplies of DW 75.

\section{REFERENCES}

Bell, P. H. (1954). 7. Amer. chem. Soc., 76, 5565.

Besser, G. M., Butler, P. W. P., and Plumpton, F. S. (1967). Brit. med. f., 4, 391 .

Boissonnas, R. A., Guttmann, S., and Pless, J. (1966). Experientia (Basel), 22, 526.

Doepfner, W. (1966). Experientia (Basel), 22, 527.

Greig, W. R., Browning, M. C. K., Boyle, J. A., and Maxwell, J. D. (1966). \%. Endocr., 34, 411.

Greig, W. R., Jasani, M. K., Boyle, J. A., and Marwell, J. D. (1968). In The Investigation of Hypothalamic-pituitary-adrenal Function edited by V. H. T. James and J. Landon, p. 176. London.

Jenny, M., Muller, A. F., and Mach, R. S. (1966). Experientia (Basel), 22, 528.

Kappeler, H., and Schwyzer, R. (1961). Helv. chim. Acta, 44, 1136.

Landon, J., James, V. H. T., Cryer, R. J., Wynn, V., and Frankland, A. W. (1964). F. clin. Endocr., 24, 1206.

Mattingly, D. (1962). F. clin. Path., 15, 374.

Nelson, J. K., Neill, D. W., Montgomery, D. A. D., MacKay, J. S., Sheridan, B., and Weaver, J. A. (1968). Brit. med. F., 1, 557.

Sayers, M. A., Sayers, G., and Woodbury, L. A. (1948). Endocrinology, $42,379$.

Schwyzer, R., and Sieber, P. (1963). Nature (Lond.), 199, 172.

Wood, J. B., Frankland, A. W., James, V. H. T., and Landon, J. (1965). Lancet, 1, 243.

\title{
Contraceptive Action of Continuous Low Doses of Norgestrel
}

\author{
G. L. FOSS,* O.B.E., V.R.D., M.A., M.D. ; E. K. SVENDSEN, †§ M.D. ; K. FOTHERBY, † PH.D., F.R.I.C. \\ D. J. RICHARDS, $\ddagger$ M.B., CH.B., B.SC.
}

Brit. med. F., 1968, 4, 489-491

\begin{abstract}
Cummary : Norgestrel in a dose of $50 \mu \mathrm{g}$. was $\checkmark$ administered daily to 188 women during 2,250 menstrual cycles. Only two pregnancies occurred because of failure of the method, giving a failure rate of 1.1 pregnancies per 100 woman-years. The method was acceptable to most of the subjects, and side-effects, other than menstrual irregularity, were minimal ; $68 \%$ of the cycles were $28 \pm 5$ days in length and $21 \%$ were less than 23 days. There did not appear to be any increased incidence of amenorrhoea. The antifertility action of continuous administration of low doses of progestogen may be due to an effect on corpus luteum function, in addition to the effects on cervical mucus, endometrium, and tubal transport of ova. The optimum dose of norgestrel appears to be in the range of 50-75 $\mu \mathrm{g}$./day.
\end{abstract}

\section{Introduction}

Martinez-Manautou et al. (1966, 1967) showed that continuous dosage with $0.5 \mathrm{mg}$. of chlormadinone acetate daily exerted an antifertility effect, though ovulation was not always inhibited. In a trial involving over 900 women for more than 8,000 cycles only one pregnancy occurred that could be attri-

* Clinical Assistant, Endocrine Clinic, United Bristol Hospitals, and Head of Bristol Male Sub-Fertility Clinic.

t Department of Steroid Biochemistry, Royal Postgraduate Medical School, London W.12.

$\ddagger$ Head of Clinical Investigation, John Wyeth \& Brother Ltd., Taplow, Maidenhead.

$\$$ Present address: Department of Obstetrics and Gynaecology, University of Bergen, Norway. buted to a failure of the method, giving a pregnancy rate of 0.2 per 100 woman-years. The Sims-Huhner test was negative in $80 \%$ of 115 women studied, and $65 \%$ of the endometrial biopsies from 202 women showed normal or irregular secretory patterns indicative of ovulation. Other studies in which the same dose of chlormadinone was used have shown a failure rate of 4.6 per 100 woman-years (Zañartu et al., 1968). The antifertility effect of low-dose progestogen treatment was ascribed to effects on the uterine endometrium or to effects on cervical mucus. The above studies involving chlormadinone acetate were carried out on South and Central American women, and it was felt desirable to test the acceptability of this type of method in British women. The results of the present paper show that norgestrel (13 $\beta$-ethyl-17 $\alpha$-ethynyl-17 $\beta$-hydroxygon4-en-3-one), a totally synthetic steroid and one of the most potent progestogens available, at a dose level of $50 \mu \mathrm{g} . /$ day exerts an antifertility effect.

\section{Subjects and Methods}

The patients admitted to the trial were seen regularly at monthly intervals; at the initial attendance the subjects were examined and information was obtained regarding parity, menstrual history, previous methods of contraception, and general medical history. Care was taken to explain in detail the method to be used. At each monthly visit details of menstruation, weight changes, possible side-effects, and other relevant data were recorded on specially printed cards. Bleeding that was not different in amount or duration from the usual pattern was recorded as menstruation. Endometrial biopsies 
were obtained from some patients; the biopsy specimens were fixed in Bouin's solution and the sections stained with haematoxylin B and Masson trichrome stain. Some of the patients collected urine on days 8 and 22 of the cycle, while others collected daily samples throughout whole menstrual cycles. The excretion of pregnanediol was measured by the method of Klopper et al. (1955) and luteinizing hormone by a radioimmuno-assay (Bagshawe et al., 1966).

All of the patients who collected urine samples had been in the trial for at least six months before collections were started. Of the 188 women in the trial who received norgestrel at a dose level of $50 \mu \mathrm{g}$. daily, 173 were aged 17 to 40 years, and 15 were aged 41 to 48 years. All except 22 recently married patients had proved themselves to be fertile, having had families of from one to nine children.

\section{Results}

A total of 2,250 cycles have been completed ; 165 of the 188 patients receiving $50 \mu \mathrm{g}$. of norgestrel completed seven or more cycles and 58 completed 20 or more cycles. Six pregnancies have occurred; four of these were patient failures-three women after two or three cycles of treatment forgot to take tablets while on holiday; the fourth had a bout of diarrhoea and vomiting in the fourth cycle at a time when conception most likely occurred. The fifth patient became pregnant after 14 cycles and the sixth after three short cycles of 12,13 and 10 days; both patients denied missing any tablets or having any gastrointestinal upset. These two cases must be accepted as tablet failures, giving a tablet failure of 1.1 per 100 womanyears. A comparison of the pregnancy rate in women taking $50 \mu \mathrm{g}$. of norgestrel daily with that of women receiving other dose levels is shown in Table I. A further 47 women left the trial ; 12 stopped contraceptive treatment because they desired a further pregnancy, seven became menopausal or were sterilized, and 18 left the district. Only 10 left the trial because of dissatisfaction with the method, seven because of cycle irregularity and three for other minor reasons.

Cycle control was less good than with a combined contraceptive. Intermenstrual spotting occurred in 75 women in 128 cycles, an incidence of $5.7 \%$ of cycles. The length of $68 \%$ of the 2,250 cycles studied was in the range $28 \pm 5$ days, $11 \%$ were longer than 33 days, and $21 \%$ were less than 23 days (Fig. 1) Of 170 patients who completed three or more cycles of treatment, 127 had a cycle shorter than 23 days on one or more occasions and only 21 patients had a record of no cycles outside the range of $28 \pm 5$ days. Side-effects were minimal ; 25 patients reported that breast tenderness occurred at some time during their treatment course. Of the patients treated for more than one year with norgestrel, 52 showed weight changes of more than $3 \mathrm{lb}$. (1,360 g.); 29 of these had a slight gain in weight, whereas 23 showed a loss.

TABLE I.-Contraceptive Effectiveness of Different Doses of Norgestrel

\begin{tabular}{|c|c|c|c|c|}
\hline \multirow{2}{*}{$\begin{array}{c}\text { Dose of } \\
\text { Norgestrel } \\
(\mu \mathrm{g} . / \text { day })\end{array}$} & \multirow{2}{*}{$\begin{array}{l}\text { No. of } \\
\text { Subjects }\end{array}$} & \multirow{2}{*}{$\begin{array}{c}\text { No. of } \\
\text { Cycles } \\
\text { Completed }\end{array}$} & \multicolumn{2}{|c|}{ Pregnancies } \\
\hline & & & Tablet Failure & Patient Failure \\
\hline $\begin{array}{c}250 \\
100 \\
50 \\
2 \times 25 \\
25\end{array}$ & $\begin{array}{r}12 \\
60 \\
188 \\
35 \\
33\end{array}$ & $\begin{array}{r}65 \\
173 \\
2,250 \\
50 \\
120\end{array}$ & $\begin{array}{l}0 \\
0 \\
2 \\
0 \\
6\end{array}$ & $\begin{array}{l}0 \\
0 \\
4 \\
2 \\
1\end{array}$ \\
\hline
\end{tabular}

Endometrial biopsies were obtained from 19 patients; in specimens obtained on the eighth day of the cycle the glands were small, some showing intraluminar polyps, the cells being mixed proliferative and early secretory. In specimens taken on the 14th to 16th days there was a dense stroma with small glands showing secretory changes. In specimens taken from the 19th to 31 st days glands were tortuous with secretory changes, spiral arterioles were evident, and some pseudodecidual areas were seen.

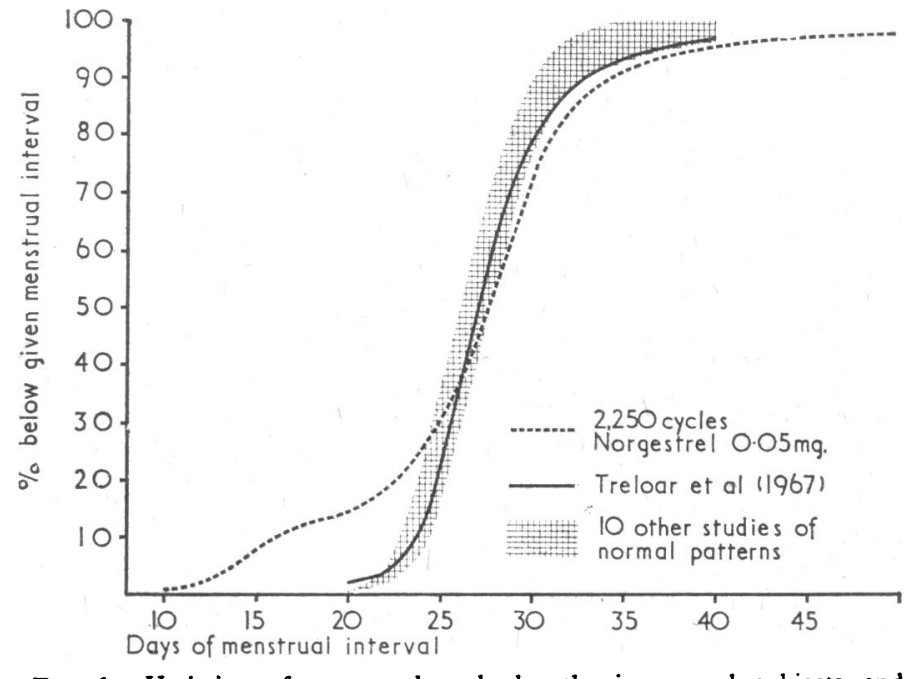

FIG. 1.-Variation of menstrual cycle lengths in normal subjects and subjects receiving $50 \mu \mathrm{g}$. norgestrel daily.

The excretion of pregnanediol by 15 of the subjects was estimated during 22 menstrual cycles. In 11 of these cycles pregnanediol excretion in the second half exceeded $2.5 \mathrm{mg}$./day and was significantly higher than the values obtained in the first half of the cycle, and was consistent with ovulation having occurred. The excretion of pregnanediol during the remaining 11 cycles is shown in Table II ; subjects for whom no day or cycle length is shown in Table II collected urine samples throughout complete menstrual cycles, and the highest value of pregnanediol excretion recorded is shown in Table II. With the exception of Subject 9 pregnanediol excretion during the second half of the cycle was at a lower level than that normally associated with the luteal phase of an ovulatory menstrual cycle and did not exceed $2 \mathrm{mg}$./day. In a previous study the mean value for pregnanediol excretion at the peak of the luteal phase was $4.5 \mathrm{mg} . / 24$ hours (Fotherby, 1962). Subject 9 excreted amounts of pregnanediol throughout the entire cycle varying from 2 to $2.5 \mathrm{mg}$./day and there was no definite increase in the second half of the cycle. Of the three subjects in Table II for whom the excretion of luteinizing hormone was measured daily, Subject 6 showed a marked rise in luteinizing hormone excretion (Fig. 2), Subject 9 showed a possible rise, and Subject 7 showed no increase.

TABLe II.-Pregnanediol Excretion During 11 Menstrual Cycles by 9 Subjects receiving $50 \mu \mathrm{g}$. Norgestrel Daily

\begin{tabular}{|c|c|c|c|}
\hline Subject & $\begin{array}{c}\text { Day of } \\
\text { Urine } \\
\text { Collection }\end{array}$ & $\begin{array}{c}\text { Cycle } \\
\text { Length } \\
\text { (Days) }\end{array}$ & $\begin{array}{c}\text { Pregnanediol } \\
\text { Excretion } \\
\text { (mg./24 Hours) }\end{array}$ \\
\hline $\begin{array}{l}1 \\
2 \\
3 \\
4 \\
5 \\
6 \\
6 \\
7 \\
8 \\
8 \\
9\end{array}$ & $\begin{array}{r}25 \\
39 \\
9 \\
23 \\
8 \\
22 \\
8 \\
24 \\
8 \\
23 \\
8 \\
23\end{array}$ & $\begin{array}{l}45 \\
32 \\
30 \\
28 \\
32 \\
31\end{array}$ & $\begin{array}{l}1.2 \\
0.7 \\
0.9 \\
1.6 \\
0.3 \\
1.2 \\
1.0 \\
0.9 \\
0.8 \\
1.1 \\
0.6 \\
0.7 \\
1.3 \\
1.5 \\
0.5 \\
0.8 \\
2.5\end{array}$ \\
\hline
\end{tabular}

\section{Discussion}

This trial shows that norgestrel at a dose level of $50 \mu \mathrm{g}$./day gave adequate contraceptive protection. Of the six pregnancies that occurred in this series, only two were due to a failure of the method, giving an overall pregnancy rate of 1.1 per 100 woman-years. The method proved to be relatively free of sideeffects, the most undesirable aspect of the method being the 

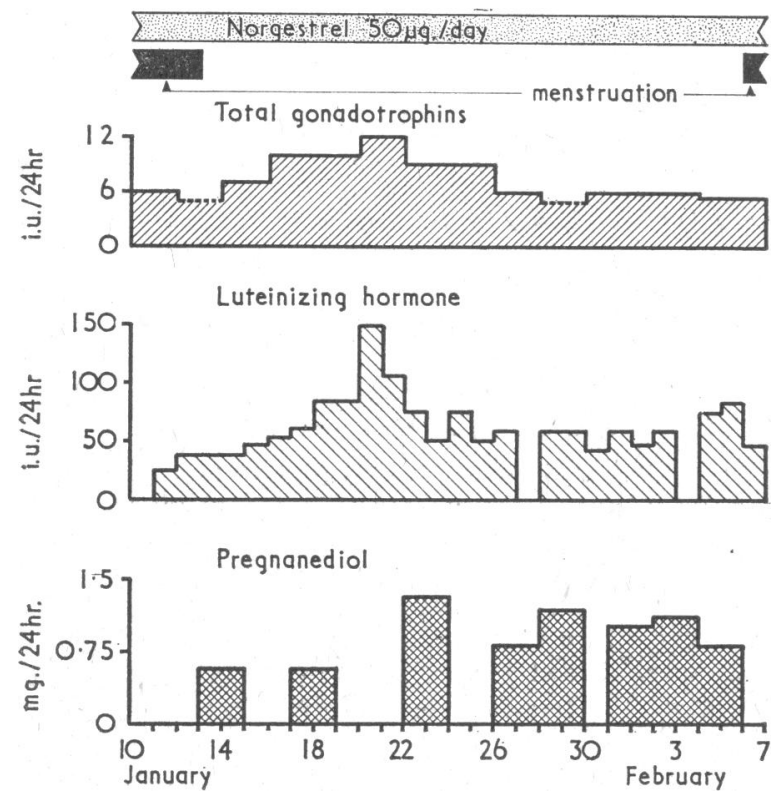

FIG. 2.-Subject 6, aged 32. Excretion of pregnanediol and gonadotrophins during a complete menstrual cycle.

irregular menstruation which occurred in many patients. However, this aspect of the method should not be unduly stressed. The combined oestrogen and progestin contraceptive pills produce a regular cycle with very little breakthrough bleeding, and the irregular menstruation experienced by some women before starting treatment usually disappears on starting treatment with a combined preparation. The incidence of irregular menstruation, therefore, in women taking the low-dose contraceptives should be compared with the normal incidence of menstrual irregularities. The variation of menstrual cycle length has recently been discussed by Treloar et al. (1967), who compared their results with those recorded in 10 other studies.

In Fig. 1 the cycle lengths recorded in the patients receiving norgestrel have been superimposed on those reported by Treloar et al. It will be seen that the menstrual cycle lengths of the patients in this study followed very closely the normal curves, except at the lower end. This shows clearly that in women taking a low-dose contraceptive there is a higher than normal incidence of cycles less than 23 days in length, but that the incidence of shorter cycles is increased by only about $10 \%$ above the normal level. There was no increased incidence of amenorrhoea in these subjects such as seems to occur in subjects taking chlormadinone acetate. There is no doubt that in the great majority of patients the method was acceptable and few complained even on direct questioning.

Various suggestions have been made regarding the mode of action of the low-dose progestogen treatment in preventing conception. The possible modes of action include (1) Effects on the cervical mucus rendering it impenetrable to spermatozoa (Mantinez-Manautou et al., 1967 ; Mason et al., 1967 ; Zañartu et al., 1968). (2) Effects on the endometrium as shown by the increased incidence of irregular bleeding in subjects taking low-dose progestins and also from results of the endometrial biopsies reported in this paper and those reported by Martinez-Manautou et al. (1967) and Zañartu et al. (1968). The effect on the endometrium could be a direct one resulting from the administered progestin or it may be an indirect one. It has been shown in animal studies that after the intravenous administration of ${ }^{14} \mathrm{C}$-norgestrel less than $0.1 \%$ of the dose is present in the uterus two to five hours later (Kamyab et al., 1967). (3) The possible effects on the tubal transport of ova.

A fourth point of action is suggested by the results presented in this paper, showing that in half the treated subjects pregnanediol excretion during the luteal phase was low and that the levels found were much lower than those associated with the luteal phase of a normal menstrual cycle. It is unlikely that the dose of norgestrel $(50 \mu \mathrm{g}$.) used in these studies would be sufficient to inhibit ovulation. Of the three subjects in whom luteinizing hormone excretion was measured one definitely and one possibly showed an increase, suggesting that ovulation might have occurred. The administered progestin may therefore interfere with the functioning and formation of the corpus luteum, resulting in an inhibition of ovarian steroid secretion. Preliminary studies in which the ovary has been examined at laparotomy in subjects treated with $50 \mu \mathrm{g}$. of norgestrel daily showed that in all cases the corpus luteum was histologically normal.

As with chlormadinone acetate the daily dose required seems to be fairly critical (Table I). Halving the dose to $25 \mu \mathrm{g}$./day was unsuccessful and seven pregnancies occurred in 33 patients treated for 120 cycles. In an attempt to minimize the incidence of irregular cycles with the $50-\mu \mathrm{g}$. dose, 35 patients were given $25 \mu \mathrm{g}$. of norgestrel twice daily for 50 cycles, but again two pregnancies resulted owing to patients forgetting to take one of the pills. Though increasing the dose to $100 \mu \mathrm{g}$./day possibly reduced the incidence of pregnancies the incidence of irregular menstruation was higher than that obtained at $50 \mu \mathrm{g}$./ day. The dose of norgestrel required would seem to be within the range $50-75 \mu \mathrm{g}$. and is therefore much lower than it is possible to use with other progestins, being about one-tenth the dose of chlormadinone acetate or of megestrol acetate used by Martinez-Manautou et al. (1967) and Mason et al. (1967) respectively. The very small dose required is obviously a great advantage, since it would be expected, as our preliminary results indicate, that side-effects would be almost absent. In addition, the norgestrel used in these studies was a mixture of the $d$ and $l$ forms of norgestrel. Only the $d$ isomer is biologically active (Edgren et al., 1963), so that it should be possible to obtain the same contraceptive efficiency with 25-35 $\mu \mathrm{g}$. of the $d$ norgestrel.

One of the main advantages of the above method is the absence of an oestrogen in the pill. The latter is generally regarded as being responsible for most of the side-effects associated with the combined oral contraceptive pill, and may be the cause of the more serious side-effects-for example, deep-vein thrombosis and pulmonary embolism (Brit. med. F., 1968). Unlike some other derivatives of $17 \alpha$-ethynyl-19-testosterone, but like chlormadinone, norgestrel seems to have little oestrogenic effect.

\section{REFERENCES}

Bagshawe, K. D., Wilde, C. E., and Orr, A. H. (1966). Lancet, 1, 1118. Brit. med. F., 1968, 2, 187.

Edgren, R. A., Smith, H., Hughes, G. A., Smith, L. L., and Greenspan, G. (1963). 'Steroids, 2, 731.

Fotherby, K. (1962). ₹. Endocr., 25, 19.

Kamyab, S., Littleton, P., and Fotherby, K. (1967). 7. Endocr., 39, 423.

Klopper, A., Michie, E. A., and Brown, J. B. (1955). ₹. Endocr., 12, 209.

Martinez-Manautou, J., Cortez, V., Giner, J., Aznar, R., Casasola, J., and Rudel, H. W. (1966). Fert. Steril., 17, 49.

Martinez-Manautou, J., et al. (1967). Brit. med. F., 2, 730.

Mason, B. A., Cox, H. J. E., Mason, D. W., and Grant, V. (1967). Postgrad. med. F., Suppl. December 1967, p. 45.

Treloar, A. E., Boynton, R. E., Behn, B. G., and Brown, B. W. (1967). Int. F. Fertil., 12, 77.

Zañartu, J., Rodriguez-Moore, G., Pupkin, M., Salas, O., and Guerrero, R. (1968). Brit. med. f., 2, 263. 